\title{
Industrial consumers' electricity market participation options: a case study of an industrial cooling process in Denmark
}

\author{
Nicolas Fatras ${ }^{1,2^{*}}$, Zheng $\mathrm{Ma}^{3}$ and Bo Nørregaard Jørgensen ${ }^{1}$ \\ From 1st Energy Informatics.Academy Conference Asia \\ Beijing, China . 29-30 May 2021
}

\footnotetext{
*Correspondence: nifa@mmmi.sdu. dk

${ }^{1}$ Center for Energy Informatics, the Maersk Mc-Kinney Moller Institute, University of Southern Denmark, 5230 Odense, Denmark

${ }^{2}$ Sino-Danish Center for Education and Research, University of Chinese Academy of Sciences, Beijing, China Full list of author information is available at the end of the article
}

\begin{abstract}
In a deregulated market context, industrial consumers often have multiple market participation options available to bid their flexible consumption in electricity markets and thereby reduce their electricity bill. Yet most participation strategies for demand response are developed in a fixed and predefined set of submarkets. Meanwhile, little literature has compared multiple market options for market participants. Therefore, this paper proposes a comparative approach between available market options to evaluate savings from different market participation options. More specifically, this study implements an optimisation program in Python to investigate the impacts of changes in an industrial process' flexibility on savings with different market participation options. The optimisation program is tested with a case study of an industrial cooling process in three Danish submarkets (day-ahead, intraday, and regulating power markets). The market participation options are formed by different combinations of these three submarkets, and the type and amount of process flexibility are varied by changing time and load constraints in the optimisation program. The results show that bidding in market options with multiple submarkets yields higher savings than single-market bidding, but that increases in available flexibility impact savings in each market option differently. Increased flexibility will only bring additional savings if it allows to take further advantage of price variations in a market option. Additionally, increases in savings with flexibility depend on the considered type of flexibility. These changes in relative savings between market options at each flexibility level imply that the optimal market option is not a static choice for a process with variable operating conditions. The optimal market option for an industrial consumer depends not only on market price signals, but also on the type and amount of available flexibility.
\end{abstract}

Keywords: Electricity market participation, Participation strategy, Market bidding, Demand response, Industrial process 


\section{Introduction}

Demand response is defined as "a shift of electricity usage in response to market price signals or certain requests" (Ma et al. 2017a). Therefore, the ability to adjust loads to respond to these signals is essential to provide demand response. Compared to commercial and residential electricity consumers (Ma et al. 2017b; Ma et al. 2016a), industrial consumers have been identified to have considerable flexibility (Paulus and Borggrefe 2011; Lund et al. 2015; Shoreh et al. 2016), which can be activated at predefined times. Traditionally, industrial consumers have offered this flexibility in electricity markets for example through compensation schemes for forced load shedding (Nolan and O'Malley 2015). (Samad and Kiliccote 2012) underlines that much more flexibility could be unlocked from industrial consumers by actively participating in electricity markets on a more continuous basis through demand response.

However, so far, demand response adoption by industrial consumers remains relatively low (Shoreh et al. 2016), and one of the main reasons is the large revenue uncertainties of providing flexibility to the electricity markets (Nolan and O'Malley 2015). Meanwhile, in many countries such as Denmark, the liberalisation of electricity markets has been accompanied by an increasing number of submarkets. These submarkets serve different purposes, such as day-ahead scheduling of supply and demand (Energinet 2007), frequency stability (Energinet 2021a), schedule adjustment to forecast changes (IRENA 2017), etc. In particular with the increase in share of variable renewable energies in the system, volumes traded in submarkets between day-ahead clearing and realtime dispatch are expected to increase (IRENA 2017). The diversity of consumption profiles and different market possibilities make it unclear for industrial consumers how to provide energy flexibility.

A market participation option can be defined as one or several submarkets in which an industrial consumer actively bids in. The potential savings from different market options will depend on the industrial consumer's available flexibility. This flexibility depends on operating requirements and preferences, which vary based on product specifications, stage of production or production schedule. Choosing the market participation option most suited to the consumer's operating conditions could increase consumers' savings and ensure a demand response solution tailored to their needs (Ma et al. 2015).

Consumers' market participation strategies have been proposed in the literature and demonstrate the economic feasibility of demand response, e.g., (Ottesen et al. 2018; Shafie-Khah et al. 2016; Böhringer et al. 2019). However, little literature has compared multiple market options for market participants, especially not for industrial consumers. There is a particular lack of focus in the literature on the operational specificities of industrial consumers when participating in multiple electricity markets.

Therefore, this paper aims to investigate the impacts of time-based and load-based flexibilities on savings in submarket participation options available to an industrial process, with a case study of an industrial cooling process in the Danish market. The industrial cooling process is chosen due to the large flexibility potential in the cooling/ freezing processes (Energianalyse 2011). Three Danish electricity sub-markets (dayahead, intraday, and regulating power markets) are chosen because they are short-term markets cleared within the scheduling timeframe of most industrial processes and are common submarkets in other countries which also implemented electricity market 
deregulation (Ma et al. 2016b). An optimisation program is implemented in Python to evaluate the savings from different market participation options. The savings in these market participation options are obtained for different time constraints and load constraints in the industrial process, to show the impact of available flexibility on each market participation option.

The paper is organised as follows: a brief overview of the related fields in the paper is introduced in the Background section. The market bidding program is described in the Methodology section followed by the case study. Results are presented and discussed in the Result and the Discussion section followed by the Conclusion section.

\section{Background}

The related fields in the paper include energy flexibility in industrial processes, Danish electricity markets, and the state of the art for evaluating industrial consumers' electricity market participation:

\section{Energy flexibility in industrial processes}

Implementing demand response in electricity markets requires to clearly identify how much of the load is flexible and can be bid in different submarkets (Ma et al. 2017c). In (Pedersen et al. 2018), two types of process flexibilities of an energy-consumer are defined: amount flexibility and time flexibility. Amount flexibility refers to the power range over which consumption can be varied at a given time (Pedersen et al. 2018). Amount flexibility is referred to as "load-based flexibility" in the rest of this study. Time flexibility refers to the time range over which the energy can be shifted before it has to match the energy consumed in the baseload (Pedersen et al. 2018), where the baseload is the initial unflexible consumption schedule. The term "time-based flexibility" will be used for this type of flexibility in the rest of this study. The time interval over which this energy deviation can occur is referred to as time-shift (Wang et al. 2013). Since demand response consists in shifting energy consumption in time, the level of demand response flexibility therefore depends on the combination of time-based flexibility and load-based flexibility. These different flexibility types are shown on the consumption profiles in Fig. 1.

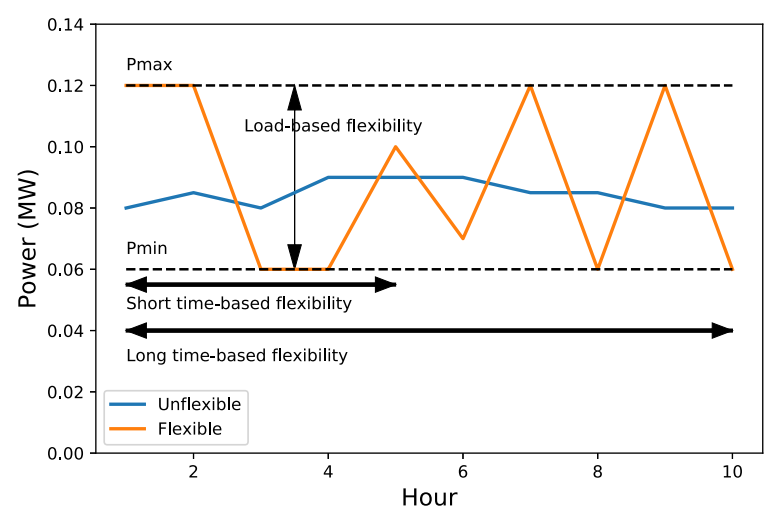

Fig. 1 Schematic of baseload vs flexible process power profiles 


\section{Danish electricity market and submarkets}

The Danish electricity market is made of several submarkets in which industrial consumers could offer demand response (Ma et al. 2016b). In this study, the submarkets included in the analysis are the day-ahead market (DA), intraday market (ID) and regulating power market (RG). All three submarkets are energy-based, i.e., trading volumes are in MWh. In the day-ahead market, consumers bid consumption volumes at an hourly resolution for the next day. In the intraday market, the cleared volumes in the DA market can be adjusted by selling or buying electricity bids, and the regulating market provides a final opportunity to adjust hourly consumption volumes. While the two first submarkets' primary functions are to schedule generation and consumption to ensure equal supply and demand on a system level, the regulating market is a balancing service cleared by the system operator. However, activation of cleared bids in all three markets is not automatic (Energinet 2007) and depends on the consumer. This implies that the industrial consumer remains in control of its load schedule, which addresses industrial consumers' reluctance to leave their load schedule to the responsibility of third parties (Cardoso et al. 2020; Ma et al. 2018). Moreover, these submarkets have high enough liquidity to be relevant for enough industrial consumers in Denmark (Nordpool 2020), and are also commonly found in other electricity markets over Europe and other parts of the world. The time sequence of chosen markets with their bidding deadlines are summarised in Fig. 2. Market participation options can also be combinations of the submarkets shown in Fig. 2.

These submarkets are cleared sequentially, so that day-ahead bids are cleared before the deadline for bidding in the intraday market, and intraday bids are cleared before the deadline for the regulating power market bids. Bids are therefore always sent with knowledge of prices in upstream markets but not downstream markets. However, as will be seen in the Methodology section, the assumption of perfect price forecasts is used in this study, which implies that bids for all markets can be planned simultaneously. Therefore, bid time constraints of the different markets are not considered further. How these different submarkets can be combined to create market participation options is explained in the next section.

\section{Market arbitrage in multiple markets}

If the submarkets for demand response bids are cleared sequentially, the consumer can participate in multiple markets, and can sell in one what was previously bought in another. This is referred to here as multiple-market participation, as opposed to singlemarket participation. In single-market participation, consumption is covered by only bidding in one market, whether flexibly or not. Sequential market clearing is common in most European electricity markets, where market participants are responsible for unit commitment (Schwabeneder et al. 2021).

The benefits of bidding in multiple markets arises when price differences occur between these markets. A consumer could decide to buy less than originally planned in a

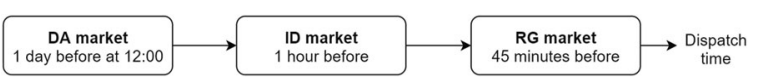

Fig. 2 Submarkets included in the study for demand response participation 
first submarket A, referred to here as upstream submarket, to then buy additional energy at a cheaper price in a later submarket B, referred to here as downstream market. One could also buy in submarket A more than originally planned and sell the surplus at a higher price in submarket B. This is referred to as market arbitrage and is illustrated below for two consecutive time steps $t_{1}$ and $t_{2}$.

An unflexible process, used as reference baseload, consumes volumes $V_{A, u 1}$ and $V_{A}$, ${ }_{u 2}$ during the hours $t_{1}$ and $t_{2}$ respectively. These electricity volumes are paid at the prices $p_{A, 1}$ and $p_{A, 2}$ of submarket A for each hour.

An equivalent flexible process can shift the consumption volume over the time interval $\left\{\mathrm{t}_{1}, \mathrm{t}_{2}\right\}$. Flexible volumes are bid in submarket $\mathrm{A}$ as $V_{A, f 1}$ and $V_{A}, f_{2}$, and in submarket $\mathrm{B}$ as $x_{B, f 1}$ and $x_{B, f 2}$, with positive values for bought volumes and negative values for sold volumes. To ensure energy consumption over the time interval $\left\{t_{1}, t_{2}\right\}$ does not deviate from the baseload energy consumption, the following constraint must be satisfied:

$$
V_{A, f 1}+x_{B, f 1}+V_{A, f 2}+x_{B, f 2}=V_{A, u 1}+V_{A, u 2}
$$

Additionally, the sum of volumes cleared in submarket A and submarket B for each hour must respect the minimum and maximum power constraints $P_{\min }$ and $P_{\max }$ which the process can deliver over an hour. Volumes cleared in market A for hour $\mathrm{t}$ are paid at price $p_{A, t}$, while volumes cleared in market $\mathrm{B}$ for hour $\mathrm{t}$ are paid or sold at price $p_{B}$, $t$.

These different variables are summarised in Fig. 3. Volumes sold on market B are represented as orange fields pointing downwards, while volumes bought on market B are represented as orange fields pointing upwards.

The saving $\mathrm{S}$ from bidding flexibly in different markets can then be expressed as follows:

$$
\begin{gathered}
S=\text { Cost }_{\text {Unflex }}-\text { Cost }_{\text {Flex }} \\
S=V_{A, u 1} * p_{A, 1}+V_{A, u 2} * p_{A, 2}-\left(V_{A, f 1} * p_{A, 1}+V_{A, f 2} * p_{A, 2}+x_{B, f 1} * p_{B, 1}+x_{B, f 2} * p_{B, 2}\right) \\
S=\left(V_{A, u 1}-V_{A, f 1}\right) * p_{A, 1}+\left(V_{A, u 2}-V_{A, f 2}\right) * p_{A, 2}-x_{B, f 1} * p_{B, 1}-x_{B, f 2} * p_{B, 2}
\end{gathered}
$$

Based on Eq. 1, $x_{B, f 1}$ in Eq. 2 can be replaced by:

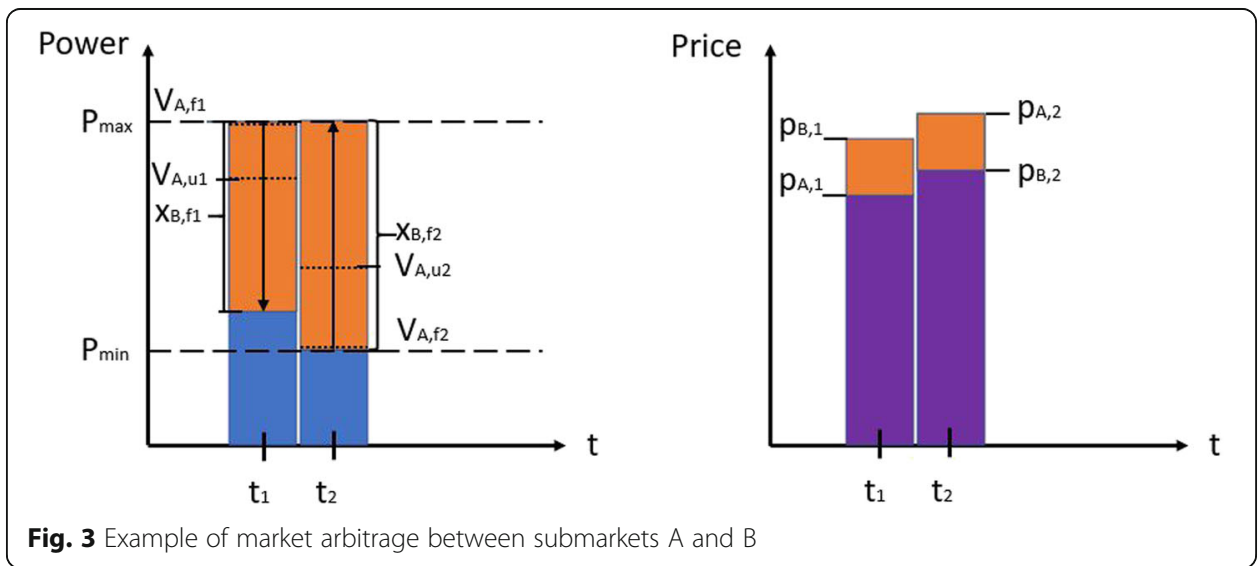




$$
x_{B, f 1}=\left(V_{A, u 1}-V_{A, f 1}\right)+\left(V_{A, u 2}-V_{A, f 2}\right)-x_{B, f 2}
$$

The following relationship can then be derived by combining Eqs. 2 and 3:

$$
\begin{aligned}
S= & \left(V_{A, u 1}-V_{A, f 1}\right) *\left(p_{A, 1}-p_{B, 1}\right)+x_{B, f 2} *\left(p_{B, 1}-p_{B, 2}\right) \\
& +\left(V_{A, u 2}-V_{A, f 2}\right) *\left(p_{A, 2}-p_{B, 1}\right)
\end{aligned}
$$

From Eq. 4, the following observations can be made:

- The term $\left(p_{A, 1}-p_{B, 1}\right)$ shows that part of the savings will be influenced by intermarket price dynamics, i.e., price differences between submarkets within the same hour

- The term $\left(p_{B, 1}-p_{B, 2}\right)$ shows that part of the savings will be influenced by intramarket price dynamics, i.e., price differences between hours within the same submarket. In case no bidding is done in market $\mathrm{B}$, this still applies for market $\mathrm{A}$.

- The term $\left(p_{A, 2}-p_{B, 1}\right)$ shows that part of the savings will be influenced by a combination of price dynamics between hours and between submarkets.

Larger time-based flexibility can yield larger savings by increasing the probability of larger price differences over the time-shift interval considered. Larger load-based flexibility can yield larger savings by maximising bid volumes at times of large price differences.

The comparison of different market participation options must therefore be done at different levels of available flexibility, to see if different options are impacted differently from changes in available flexibility.

\section{Market manipulation prevention}

To maximise savings, Eq. 4 indicates that consumers participating in multiple markets are encouraged to maximise their load deviations from their baseload consumption to then readjust the schedule in subsequent markets at more favourable prices. Since in this study market bidders have access to perfect price forecasts, this would allow to bid in one market at much higher values than is physically possible, and adjust the volume in a subsequent market at a beneficial price difference without the risk of bids not getting cleared. However, the Danish law implements the EU's Regulation for Wholesale Energy Market Integrity and Transparency (REMIT), which aims to prevent market manipulation (Danish_Energy_Agency 2020). Market manipulation can occur when giving misleading demand signals or artificially influencing prices to one's advantage (ACER 2020). Under or over bidding in upstream markets at values not physically realistic would cause such misleading demand signals. To avoid such unacceptable market behaviour, this analysis considers that the consumer must be able to physically consume any bid sent to upstream markets, even if downstream markets are not cleared. 


\section{Evaluation methods for industrial consumers' electricity market participation}

Different market evaluation methods have been applied for different types of submarkets. For day-ahead scheduling of demand response, (Strobel and Abele 2018) evaluates the economic potential of industrial heating and cooling devices bidding flexibly in the day-ahead market by implementing a decentralised control strategy based on fuzzy controllers in an agent-based model. (Zhang and Hug 2015) models an electrolytic process for aluminium smelting bidding in the MISO market through a mixed-inter linear program. (Værbak et al. 2019) evaluates the demand response adoption rate of water reservoir pumps participating flexibly in the Danish day-ahead market by implementing a heuristic control approach in an agent-based model.

For regulating power markets, (O'Connell et al. 2014) simulates the participation of a supermarket refrigeration system in the Danish regulating power market by implementing a model-predictive control architecture. (Ma and Jørgensen 2018) evaluates the economic benefits in the same market for a greenhouse lighting process using results from the climate control software DynaLight NG.

For consumer retail markets, an example is found in (Li and Hong 2016), which analyses the case of discrete manufacturing facilities bidding in a retail market by defining a mixed integer programming problem.

Yet a particularly large share of market bidding strategies in the literature focuses on stochastic optimisation, as noted in (Schwabeneder et al. 2021), particularly for multiple-market bidding strategies. In (Bohlayer et al. 2018), a stochastic mixed-integer linear program is implemented to optimise demand side management of a milling process in consecutive energy markets in Germany. (Böhringer et al. 2019) proposes a stochastic programming approach for bidding optimisation of a generic flexible factory in the German balancing and day-ahead markets. (Ding et al. 2015) uses a stochastic quadratic programming with a quantified risk term to minimise procurement volatility risk when participating in the forward, day-ahead and real-time markets. Stochastic programming is particularly relevant when participating in multiple submarkets cleared consecutively, as is common for many European electricity markets (Schwabeneder et al. 2021). Indeed, the main purpose of a stochastic approach is to reduce financial risk due to future market price uncertainties. However, the focus remains on optimising bidding in a preselected choice of submarkets.

Comparisons of multiple market options available to market participants remain rare. In (Pinto et al. 2015), an adaptive portfolio optimisation method based on particle swarm optimisation is proposed for a generator participating in multiple submarkets. The optimal bid volumes in different markets are determined based on forecasted prices in each submarket. (Schwabeneder et al. 2021) compares results for an aggregator participating in a fixed-price market, a day-ahead market and a portfolio of day-ahead, intraday and balancing market in a European context. However, neither of these studies focuses on the operational specificities of industrial consumers participating in electricity markets.

\section{Methodology}

This section will first cover the assumptions taken for the optimisation program, then it will present the optimisation approach in the different market options and the relevant constraints. 


\section{Assumptions for market participation evaluation}

The quantitative analysis in this study is based on a series of assumptions which make it an upper-bound approach. The purpose of such an approach is to evaluate the impact of operating conditions on the electricity bill savings from different market participation options, without being affected by behavioural factors or uncertainties on external factors which can impact different market options to different degrees. Behavioural factors such as risk-willingness will only degrade such optimistic evaluations. Therefore, an upper-bound approach is important to assess whether maximum gains are enough to trigger participation interest, before improving the accuracy of revenue estimates.

The following key assumptions are taken:

- Risk-neutral bidding: industrial consumers are risk neutral when planning their submarket participation strategy. As will be discussed later, different submarket options have different operational risk levels, but these are not considered when optimising the bidding schedule.

- Perfect price forecast: when scheduling market bids, it is assumed that industrial consumers have access to exact market clearing prices, based on perfect price forecasts made available before bidding. This is made possible due to the use of historical market prices in this analysis. This is particularly interesting when participating in markets with sequential clearing, since upstream market participation can be optimised while knowing prices in markets cleared later. Market activity forecasts are also included to know whether a submarket will be active or not.

- Price taker: The use of historical price data assumes the industrial consumer is a price taker, meaning it does not have influence on the market prices. This is only reasonable if flexible industrial consumers represent a small part of the overall electricity system. This assumption gives results which are valuable for early adopters when evaluating the economic viability of market entry, as historic data ensures realistic scenarios. However, as the share of flexible industrial consumers participating in the market increases, updated or forecasted market prices would have to be used instead, as increasing flexible demand could create undesirable load peaks from consumer synchronisation at times of low prices (Kühnlenz et al. 2018; Krause et al. 2015).

- No market intermediary service fees: the entity bidding in the electricity market on behalf of the industrial consumer does not charge for this bidding service. This allows industrial consumers to act directly based on market prices, without being influenced by any tariffication from a third-party market actor. Since industrial consumers are often large enough to trade directly in the wholesale market without passing through aggregators (Kirschen 2003), such third-party fees would in reality be rather small.

- Focus on electricity market prices: taxes and network tariffs are excluded from the electricity price, as these depend on the size of the consumer but generally represent a lower share of the final electricity bill compared to private households in Denmark (Ropenus and Jacobsen 2015). Since taxes and tariffs are fixed per unit of energy consumed (Ropenus and Jacobsen 2015), they can be added as fixed costs after the market evaluation is done. 
- No imbalance: industrial consumers are assumed to follow the power schedule cleared in the market. This avoids paying compensations to the transmission system operator for imbalances between electricity loads cleared on the market and loads physically consumed. Load deviations would occur in case of unexpected logistical changes, upstream or downstream delays in the production, or operational inaccuracies. Such deviations would be caused by the consumers, which usually prioritise the optimisation of their main revenue-generating processes before optimising savings on their electricity bill (Grein and Pehnt 2011).

The above-mentioned points give an overestimate of potential revenues from market participation but allow to compare submarket options without including subjective behavioural factors or uncertain external factors. This allows to focus on the impact of process flexibility alone on market option results.

\section{Bidding optimisation for market options}

An optimisation program is implemented in this paper to evaluate savings from the market participation options which are made of different submarket combinations. The different options analysed in this study for the three chosen submarkets are presented in Table 1.

The bid volumes and prices for all submarkets in each option are decided before the deadline of the first market, in this case the day-ahead market. Since perfect price forecasts are used, this does not affect the clearing probability of bids in submarkets with later bidding deadlines. Single-market options implement flexible bidding in only one submarket. For the ID and RG submarkets, this implies unflexible bidding in the DA submarket in order to adjust the baseload in these downstream submarkets. Multiple-market options imply flexible bidding in at least two submarkets. The savings obtained from each option are calculated by comparing the electricity bill of each market participation option with the electricity bill of the unflexible operating case. The bidding logic for each of these options is implemented with a deterministic linear program presented below.

\section{Objective function}

The program's objective for a given market participation option is to determine the bid volume in each active submarket for each time interval of the next day. The constraints

Table 1 Applied market participation options

\begin{tabular}{ll}
\hline Market participation option & Bidding approach \\
\hline Unflexible & Bid unflexible initial baseload in day-ahead market \\
Day-ahead market (DA) & Optimise scheduled loads based on day-ahead market prices \\
Intraday market (ID) & Adjust initial baseload with bids in intraday market \\
Regulating power market (RG) & $\begin{array}{l}\text { Adjust initial baseload with up/down bids in regulating power } \\
\text { market }\end{array}$ \\
Day-ahead and intraday market (DA + ID) & $\begin{array}{l}\text { Optimise scheduled loads by bidding in day-ahead and intraday } \\
\text { market }\end{array}$ \\
$\begin{array}{ll}\text { Day-ahead and regulating power market } \\
\text { (DA + RG) }\end{array}$ & $\begin{array}{l}\text { Optimise scheduled loads by bidding in day-ahead and regulating } \\
\text { power market }\end{array}$ \\
All three sub-markets (DA + ID+RG) & Optimise scheduled loads by bidding in all three sub-market \\
\hline
\end{tabular}


of the optimisation problem are given by the process flexibility limits and by each submarket's requirements, including the restrictions imposed to avoid market manipulation through market arbitrage. Including all submarkets in this analysis, the convex linear program to solve each day is, therefore:

$$
\begin{aligned}
\text { min Daily Electricity Bill }= & \min _{x_{D A}, x_{I D}, x_{R G}} \sum_{t=1}^{24} a_{\text {unflexible }} c_{D A}(t) x_{\text {unflexible }}(t) \\
& +a_{D A} c_{D A}(t) x_{D A}(t)+a_{I D} c_{I D}(t) x_{I D}(t) \\
& +a_{R G} c_{R G}(t) x_{R G}(t)
\end{aligned}
$$

$a_{\alpha}$ is a binary value that indicates whether submarket $\alpha$ is included in the considered market participation option. $a_{\text {unflexible }}$ and $a_{D A}$ cannot be both active in the same market option, as they both represent bids in the day-ahead market and are therefore mutually exclusive. $c_{D A}, c_{I D}$ and $c_{R G}$ are the price forecasts for each market and $x_{D A}, x_{I D}$ and $x_{R G}$ are the bid volumes for each market.

Since perfect price forecasts are assumed, bidding is done deterministically without considering different price scenarios. The process constraints and three electricity submarket constraints described below are added to the objective function, with constraint values changing depending on the flexibility of the process and the number of constraints changing depending on the number of submarkets chosen in a particular market participation option.

Process constraints.

At any time step, the energy effectively consumed by the industrial process is denoted as:

$$
\operatorname{Load}(t)=a_{\text {unflexible }} x_{\text {unflexible }}(t)+a_{D A} x_{D A}(t)+a_{I D} x_{I D}(t)+a_{R G} x_{R G}(t) \forall t
$$

For the submarkets considered, the loads $x$ represent energy volumes, but also represent power volumes in this analysis, since power consumption is assumed constant for each time step.

The power limits of load-based flexibility can then be described with the following constraint:

Constraint $1 P_{\min }(t) \leq \operatorname{Load}(t) \leq P_{\max }(t) \forall t$

$P_{\min }(t)$ and $P_{\max }(t)$ respectively represent the minimum and maximum power required to satisfy process operations at each time step. The difference between these two values represents the process' load range.

The time-shift limit of the time-based flexibility yields the following energy balance constraint:

$$
\text { Constraint } 2 \sum_{t=T_{0}}^{T_{0}+T S} \operatorname{Load}(t)=\sum_{t=T_{0}}^{T_{0}+T S} E_{\text {unflexible }}(t) \forall\left\{T_{0} ; T_{0}+T S\right\} \in\{0,24\}
$$

$E_{\text {unflexible }}(t)$ is the energy required by the process based on the unflexible power profile, TS is the time-shift interval over which the energy consumed in the unflexible and the flexible cases have to match, and $T_{0}$ is the start time of each time-shift interval. This constraint ensures that the energy needs of the process are satisfied within a certain time interval TS. Larger TS values give more process flexibility. This constraint creates time interdependency between market hours. 


\section{Day-ahead market constraints}

The logic of the optimisation program in the day-ahead market is:

- Bidding information: consumers can only submit consumption (positive) bids in the day-ahead market, with the volume and bidding price of bids at an hourly resolution for the $24 \mathrm{~h}$ of the next day. Additionally, consumption bids must respect the maximum power capacity of the consumer to be physically feasible and avoid market manipulation.

- Clearing mechanism: All consumption bids at a price above clearing price are cleared. Since in this analysis clearing prices are known in advance, bids are always submitted above clearing price to ensure market clearing.

Since bids in the day-ahead market can only be positive, i.e., consumption bids, and respect maximum power capacity, the following constraints apply:

Constraint $30 \leq x_{D A}(t) \leq P_{\max }(t) \forall t$

As mentioned above, if bidding in the day-ahead market is not flexible, then the dayahead volume is set to the unflexible load schedule.

$$
\begin{array}{cc}
\text { if } a_{D A}=0: \\
\text { Constraint } 4 \quad \begin{array}{c}
a_{\text {unflexible }}(t)=1 \\
\text { else } a_{\text {unflexible }}(t)=0
\end{array}
\end{array}
$$

\section{Intraday market constraints}

The logic of the optimisation program in the intraday market is:

- Bidding information: in this study, the intraday market bid volume and bid price for each hour of the next day is decided at the same time as the bids for the day-ahead market, even if the intraday bids are submitted at a later stage in reality. Industrial consumers can either sell excess electricity or buy additional electricity.

- Clearing mechanism: the intraday market is a bilateral exchange market cleared centrally by the market operator (Nordpool Elbas) on a continuous basis. A bid is therefore only cleared if a corresponding buyer or seller is found at the bidding price (pay-as-bid). Bids in this analysis are submitted at average historical cleared price to maximise clearing likelihood, which makes the assumption of guaranteed bid clearing acceptable.

Bids in the intraday market can be positive or negative but must also be physically feasible. Therefore, the following constraints apply:

Constraint 5

$$
-P_{\max }(t) \leq x_{I D}(t) \leq P_{\max }(t) \forall t
$$

Additionally, if the intraday activity forecast $V_{I D \text {-forecasted }}$ predicts that the intraday market will not be active or if forecasted average prices are equal to day-ahead market prices, an additional constraint is added: 


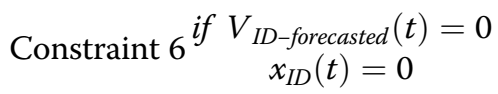

\section{Regulating power market constraints}

The logic of the optimisation program in the Regulating power market is:

- Bidding information: in this study, the regulating market bid volume and bid price for each hour of the next day is decided at the same time as the bids for the dayahead and intraday market, even if the regulating market bids are submitted at a later stage in reality. Industrial consumers can either sell excess or buy additional electricity. Bids for up-regulation (consumers selling electricity) and downregulation (consumers buying electricity) must be done separately. If the regulating price forecast is above the day-ahead price, then up-regulation is needed and consumers are encouraged to sell, implying negative bids. If the regulating price forecast is below day-ahead price, then down-regulation is needed and consumers are encouraged to buy, implying positive bids. If the regulating price forecast is equal to the day-ahead price or if volume forecasts predict that the regulating market will not be active, then bid volumes are set to 0 . Clearing mechanism: Bids are cleared at a uniform price, which is above DA market price in case of up-regulation or below DA market price in case of down-regulation. When no regulating power is needed, cleared volumes are set to zero. Bids in the regulating power market are only cleared if they are in the direction in which regulating power is needed in the system.

The bidding logic in the regulating power market is translated into the following constraint:

$$
\begin{gathered}
\text { if } c_{R T}(t)-c_{D A}(t)>0 \\
x_{R T}(t)<0 \\
\text { Constraint } 7 \text { else if } c_{R T}(t)-c_{D A}<0 \\
x_{R T}(t)>0 \\
\text { if } V_{R T-\text { forecasted }}(t)=0 \\
x_{R T}(t)=0
\end{gathered}
$$

\section{Solving the optimisation program}

The objective function with its set of constraints is solved in Python using the embedded conic solver ECOS (Domahidi et al. 2013), provided by the cvxpy library. An example of optimised bidding schedule over a day is shown below in Fig. 4:

The program is fed with daily data inputs for the baseload, the submarket prices and activation forecasts. The main output used to compare market participation options is the value of the objective function, which represents the daily electricity bill.

\section{Case study}

The industrial process analysed in this study is a cooling system for a meat processing factory for which cooling temperature data was provided. In this factory, cuttings of meat are delivered in batches and stored in large cooling rooms to avoid food spoilage 


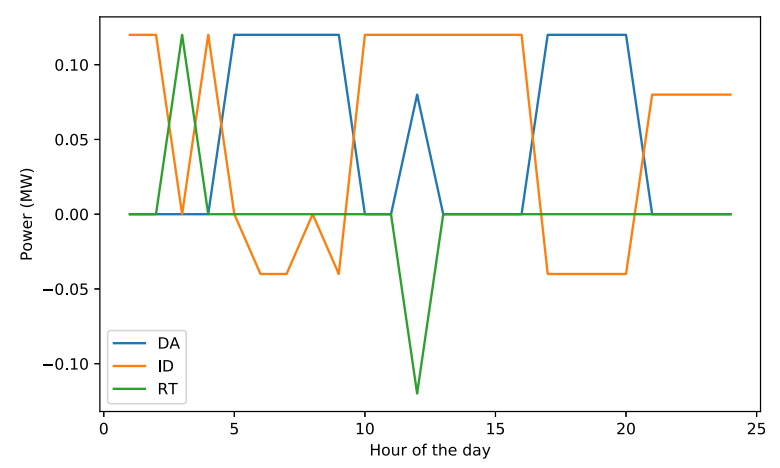

Fig. 4 Optimal bidding schedule based on linear program results

while waiting to be processed further. When the meat moves down the production line, it passes through different rooms which each have their own set point temperature, a lower- and upper-bound temperature, and a maximum duration of allowed temperature deviation from the bounds before setting off an alarm. These process properties are the operating requirements, which also vary based on the product being processed. These rooms are all cooled through a central refrigeration system which can operate over a continuous range up to maximum power.

The described process can be considered to have both varying load-based flexibility and time-based flexibility, depending on the room and product considered. The consumer could therefore bid different amounts of flexibility in the electricity market depending on the process considered for flexible market bidding. To simplify the analysis, changes in flexibility are simulated by varying temperature requirements in one room only.

This case study investigates how variations in process temperature requirements affect the savings in different market participation options:

- Scenario 1 (S1): time-based flexibility is changed by varying the allowed time-shift interval from $1 \mathrm{~h}$ to $24 \mathrm{~h}$. Time-shift values are chosen to have a complete number of time-shift intervals within a day. The allowed temperature range in this case goes from $0.5^{\circ} \mathrm{C}$ to $5^{\circ} \mathrm{C}$. The lower bound temperature is set to $0.5^{\circ} \mathrm{C}$ to avoid freezing, which could damage the processed goods. The upper temperature limit is based on data provided for the analysed industrial process.

- Scenarios 2 and 3 (S2 and S3): load-based flexibility is changed in two different ways:

- Scenario 2 (S2): only the upper-bound temperature is changed, while the lower bound is fixed to $0.5^{\circ} \mathrm{C}$ to prevent going below freezing point.

- Scenario 3 (S3): both lower and upper bound temperature are changed symmetrically compared to the baseload case. This scenario is more hypothetical, since it does not respect the freezing point constraint, but it illustrates the impact of different load range constraints on electricity bill savings.

The two load-based flexibility scenarios therefore have equal flexibility in terms of load range, but this flexibility is applied over different temperature limits. The time- 
shift capacity for both load-based flexibility scenarios is fixed to $24 \mathrm{~h}$ and the unflexible baseload is assumed to have temperatures varying between $0.5^{\circ} \mathrm{C}$ and $4{ }^{\circ} \mathrm{C}$.

The specific scenarios implemented are summarised in Table 2:

The indoor cooling temperature for the baseload consumption is provided with an hourly resolution from June 1st 2020 to June 30th 2020. To bid in electricity markets, the room temperature must be translated into a power consumption $\mathrm{P}$ for the refrigeration system. Since modelling the exact thermal dynamics of the process is not the aim of this study, a crude approximation based on basic heat transfer theory is used, with the relationship between power consumption, internal temperature $T_{i}$, and external temperature $T_{a}$ shown below:

$$
P(t)=\alpha\left(T_{a}(t)-T_{i}(t)\right)
$$

$\alpha$ depends on the thermal properties of the building and the thermal efficiency of the cooling system and is approximated based on power consumption data given with an hourly resolution for a week in October 2019. $T_{a}$ is obtained from Danish Meteorological Institute API (DMI 2021), at an hourly resolution for June 2020. For more accurate results adapted to a specific industrial process, the case study can be reused and adapted by improving the physical representation of the industrial process.

Once the temperature limits in Table 2 have been translated into power limits using Eq. 14, each row in each scenario of Table 2 represents constraints in a different optimisation problem. Each problem is solved for all market options to obtain the electricity bill under the tested operating conditions. The daily bill, corresponding to the objective function of the optimisation program, is then compared with the daily bill of the unflexible load to conclude on savings from each market option. The unflexible load is billed at hourly day-ahead market prices but does not react to price signals.

These different flexibility scenarios are run over the entire month of June 2020 based on the available temperature data for the baseload cooling process. The historical market prices for the considered markets, shown in Fig. 5, are taken from Energinet's Data Portal over the considered time range. Figure 5 uses a 12-h moving average to smooth out price peaks for visualisation purposes, but the data in the analysis is based on an hourly time resolution.

Table 2 Flexibility parameters used in different model scenarios

\begin{tabular}{|c|c|c|c|}
\hline $\begin{array}{ll}\text { Flexibility level } & \text { Flexibility type } \\
\end{array}$ & $\begin{array}{l}\text { Scenario } 1^{*} \\
\text { (S1) }\end{array}$ & $\begin{array}{l}\text { Scenario } 2^{\star *} \\
\text { (S2) }\end{array}$ & $\begin{array}{c}\text { Scenario } 3^{* * *} \\
\text { (S3) }\end{array}$ \\
\hline \multirow{6}{*}{ Low flexibility } & $1 \mathrm{hrs}$ & $3.5^{\circ} \mathrm{C}\left(0.5^{\circ} \mathrm{C}\right.$ to $\left.4^{\circ} \mathrm{C}\right)$ & $3.5^{\circ} \mathrm{C}\left(0.5^{\circ} \mathrm{C}\right.$ to $\left.4^{\circ} \mathrm{C}\right)$ \\
\hline & $2 \mathrm{hrs}$ & $4.5^{\circ} \mathrm{C}\left(0.5^{\circ} \mathrm{C}\right.$ to $\left.5^{\circ} \mathrm{C}\right)$ & $4.5^{\circ} \mathrm{C}\left(0^{\circ} \mathrm{C}\right.$ to $\left.4.5^{\circ} \mathrm{C}\right)$ \\
\hline & $4 \mathrm{hrs}$ & $5.5^{\circ} \mathrm{C}\left(0.5^{\circ} \mathrm{C}\right.$ to $\left.6^{\circ} \mathrm{C}\right)$ & $5.5^{\circ} \mathrm{C}\left(-0.5^{\circ} \mathrm{C}\right.$ to $\left.5^{\circ} \mathrm{C}\right)$ \\
\hline & $8 \mathrm{hrs}$ & $6.5^{\circ} \mathrm{C}\left(0.5^{\circ} \mathrm{C}\right.$ to $\left.7^{\circ} \mathrm{C}\right)$ & $6.5^{\circ} \mathrm{C}\left(-1^{\circ} \mathrm{C}\right.$ to $\left.5.5^{\circ} \mathrm{C}\right)$ \\
\hline & $12 \mathrm{hrs}$ & $7.5^{\circ} \mathrm{C}\left(0.5^{\circ} \mathrm{C}\right.$ to $\left.8^{\circ} \mathrm{C}\right)$ & $7.5^{\circ} \mathrm{C}\left(-1.5^{\circ} \mathrm{C}\right.$ to $\left.6^{\circ} \mathrm{C}\right)$ \\
\hline & 24hrs & $8.5^{\circ} \mathrm{C}\left(0.5^{\circ} \mathrm{C}\right.$ to $\left.9^{\circ} \mathrm{C}\right)$ & $8.5^{\circ} \mathrm{C}\left(-2^{\circ} \mathrm{C}\right.$ to $\left.6.5^{\circ} \mathrm{C}\right)$ \\
\hline \multicolumn{4}{|c|}{$\begin{array}{l}\text { * Time-based flexibility: max time-shift } \\
\text { **Load-based flexibility with max temperature adjustment: load range (min to max temperature) } \\
\star \star \star L o a d-b a s e d \text { flexibility with min-max temperature adjustment: load range (min to max temperature) }\end{array}$} \\
\hline
\end{tabular}




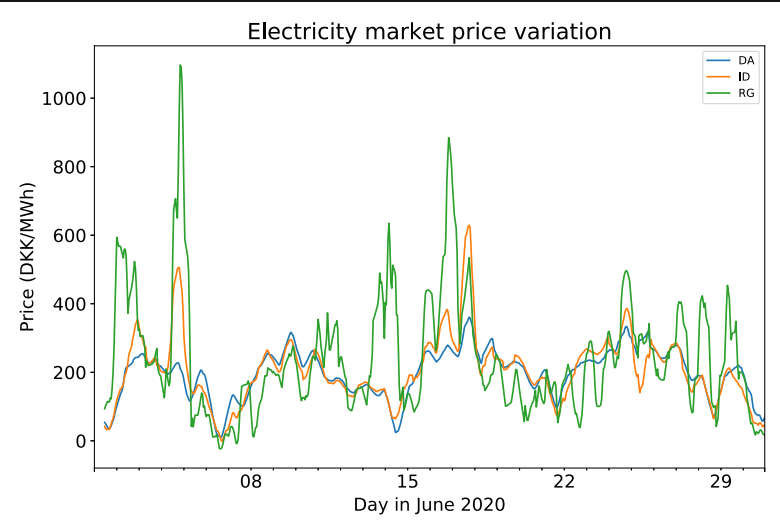

Fig. 5 Electricity markets' price variation

\section{Results}

The results investigate the impacts of time-based and load-based flexibilities in the industrial process (shown in Table 2) on the submarket participation options (shown in Table 1):

\section{Impact of time-based flexibility on market participation options}

Figure 6 shows the average daily electricity bill over the month of June 2020, obtained for different market participation options under different process time-shift capacities of scenario 1. A time-shift of zero represents the unflexible case, higher time-shift values imply higher time-based flexibility. Bill payments are represented as negative values.

The saving generated at a flexibility level is seen by the difference of the electricity bill with the bill value at zero time-shift capacity. Absolute bill values are shown in Fig. 6 for illustrative purposes, but more general observations can be made on a comparative basis between market options. Overall, single market participation options yield much lower savings than multiple market options. A large share of savings in multiple market options already occur within a time-shift capacity of $1 \mathrm{~h}$. This indicates that most savings are generated from inter-market price differences within the same hour, through market arbitrage. Further increases in time-based flexibility bring little marginal benefits when bidding in multiple markets, apart in the regulating power market.

The regulating power market on its own yields less savings than the intraday market, despite higher price variations shown in Fig. 5. This is due to the lower activation rates in the regulating market: on average in June $2020,16 \%$ of hours in the day needed upregulation, while $11 \%$ needed down regulation, implying $77 \%$ of hours without any regulating power (Energinet 2021b). In contrast, intraday exchange was possible at nearly all hours over June 2020 (Energinet 2021b). The larger price variations in the regulating power market become advantageous once they are combined with flexible day-ahead bidding. Inter-market price differences can then be exploited by adjusting bids in other markets in the same hour.

To get a better understanding of the relationship between savings and available flexibility, the following savings ratio is used for each market participation option: 


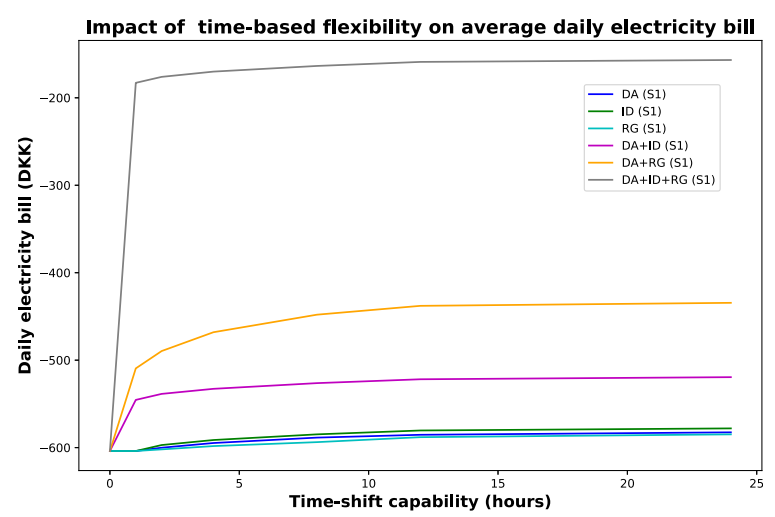

Fig. 6 Daily electricity bill depending on time-shift capacity (scenario 1)

$$
\text { Relative savings }=\frac{\text { bill }_{T S}-\text { bill }_{\text {unflex }}}{\text { bill }_{\text {maxflex }}-\text { bill }_{\text {unflex }}}
$$

bill $_{\text {unflex }}$ represents the electricity costs with no flexibility, i.e., when $T S=0$, while billmaxflex represents the electricity costs with full time-shift flexibility over $24 \mathrm{~h}$. The relative savings are then plotted for each market participation option as a function of timeshift capacity in Fig. 7.

In the day-ahead and intraday markets, relative savings quickly increase at small time-shift values and flatten out for larger time-shift values. In both cases, around $50 \%$ of maximum savings are already possible when increasing time-shift from 1 to $4 \mathrm{~h}$. The marginal benefits from an increase in flexibility is therefore higher at low flexibility values than at high flexibility values. Industrial consumers with low but variable flexibility conditions could therefore expect higher fluctuations in savings than consumers operating at high but variable flexibility conditions. Indeed, above a certain time shift capacity, further increases in time shift do not considerably increase possible price differences between and within submarkets, which according to Eq. 4 influence savings. Moreover, absolute savings shown in Fig. 6 seem too low to encourage market participation in this case, and the differences between single-market options seem too low to make one option more attractive than the other at a given level of flexibility. The regulating market trends are less clear due to the infrequent market activation rates, as explained above, which create many days with no savings.

For multiple markets, relative savings are already high at time-shifts of $1 \mathrm{~h}$, as observed in Fig. 6. Further increases in flexibility yield limited marginal benefits, particularly for the option bidding in all three markets.

\section{Impact of load-based flexibility on market participation options}

Figure 8 shows average daily electricity costs over the month of June 2020, obtained for each market participation option under different load-based flexibilities, depending on the temperature interval tolerated by the processed product in scenarios 2 and 3 . The full lines represent the scenarios where the temperature range is increased by increasing the upper temperature limit only, while leaving the lower temperature limit above freezing point. The dashed lines represent the scenarios 


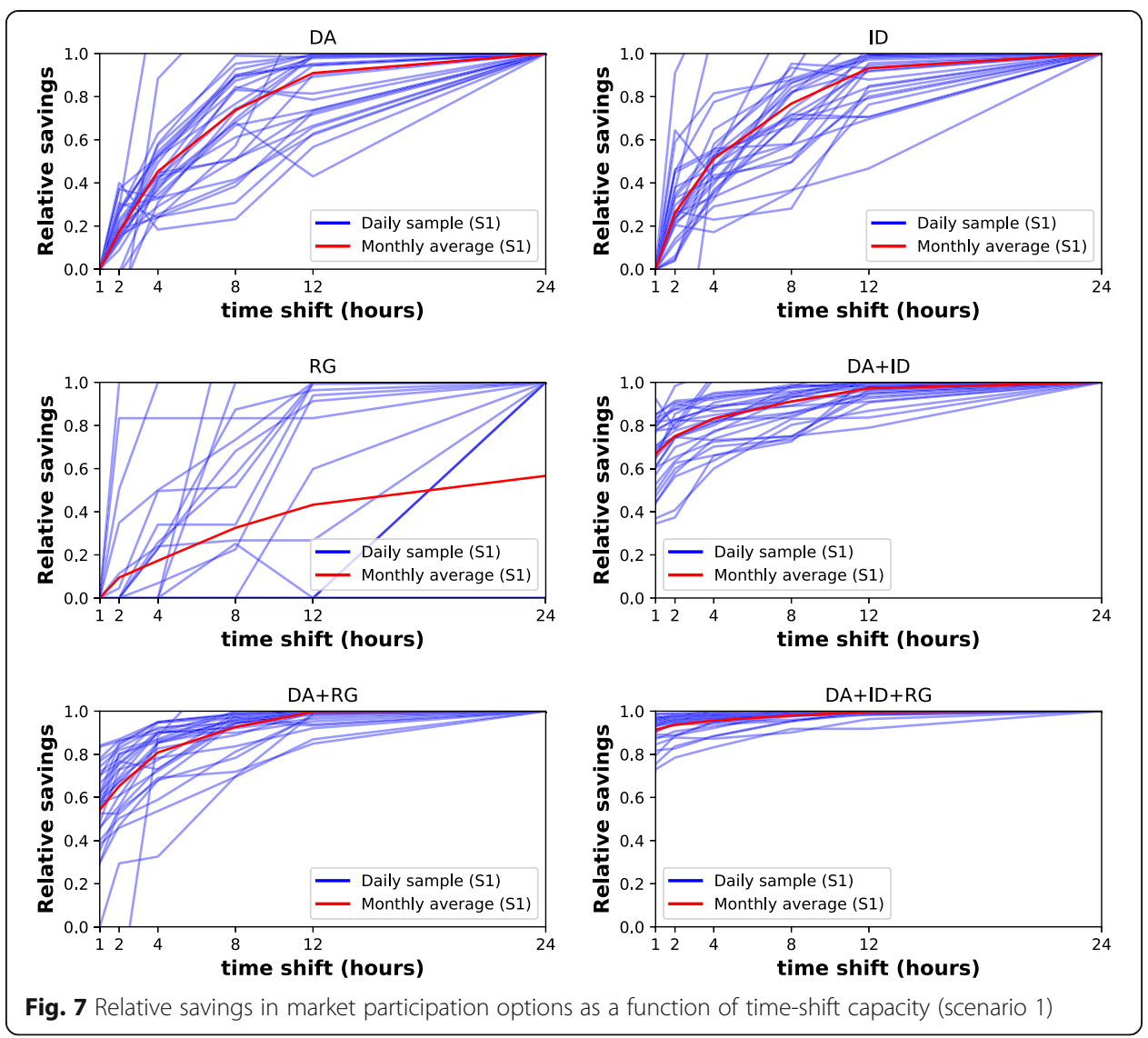

where the temperature range is increased by both increasing the upper temperature limit and decreasing the lower temperature limit. The load range of zero represents the unflexible baseload.

Again, multiple-market options yield much higher savings than single-market options. For the market data considered, single-market options generate very small savings and the difference in savings between single-market options is negligible. In this case however, different sensitivities to available flexibility are observed for the two different temperature range scenarios.

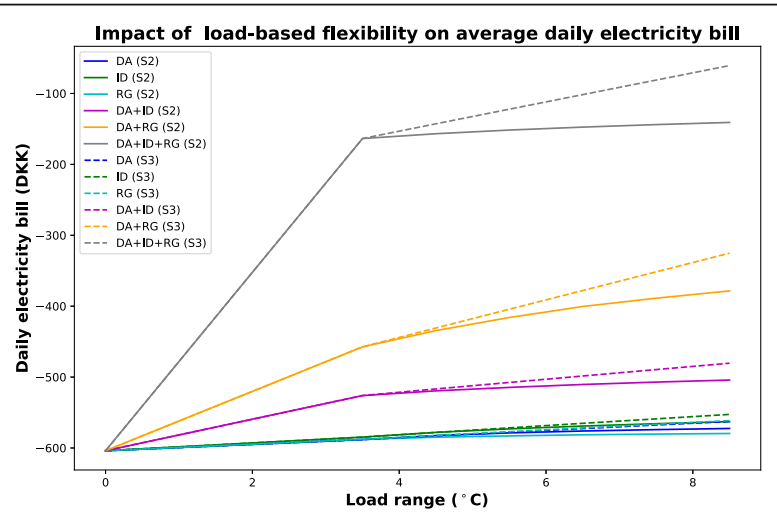

Fig. 8 Daily electricity bill depending on tolerated temperature load range (scenarios 2 and 3) 
For the full lines, where only the upper temperature limit increases, marginal benefits from additional flexibility quickly reduce to zero, as larger deviations above baseload temperature cannot be compensated by larger deviations below baseload temperature.

On the other hand, if the temperature limits move away from the baseload symmetrically, as is the case for the dashed lines, Fig. 8 shows a much more continuous increase in savings with additional load-based flexibility in all market options. For industrial consumers, deviations from the unflexible baseload are only possible if they can be compensated with equivalent deviations from the baseload in the other direction at a later point in time. Load deviations are therefore limited if flexibility only increases in one direction. In this case, the saturation in savings is caused by the energy constraint in Eq. 8 which requires as much deviations above as below the baseload.

Figure 9 shows the relative savings in each market participation option depending on the available load range. Full lines represent the scenario with a load range increase through upper temperature increase only, while dashed lines represent the scenario with load range increase in both directions.

In all cases, the marginal increase in savings is more gradual, with still significant saving improvements to be made when increasing the load range from $6.5^{\circ} \mathrm{C}$ to $8.5^{\circ} \mathrm{C}$ temperature difference. However, the full lines show a tendency for savings saturation, shown by reducing marginal benefits in savings as the temperature limit increases. Meanwhile the dotted lines increase more linearly, as larger temperature deviations at higher temperatures can be compensated with larger deviations at lower temperatures.

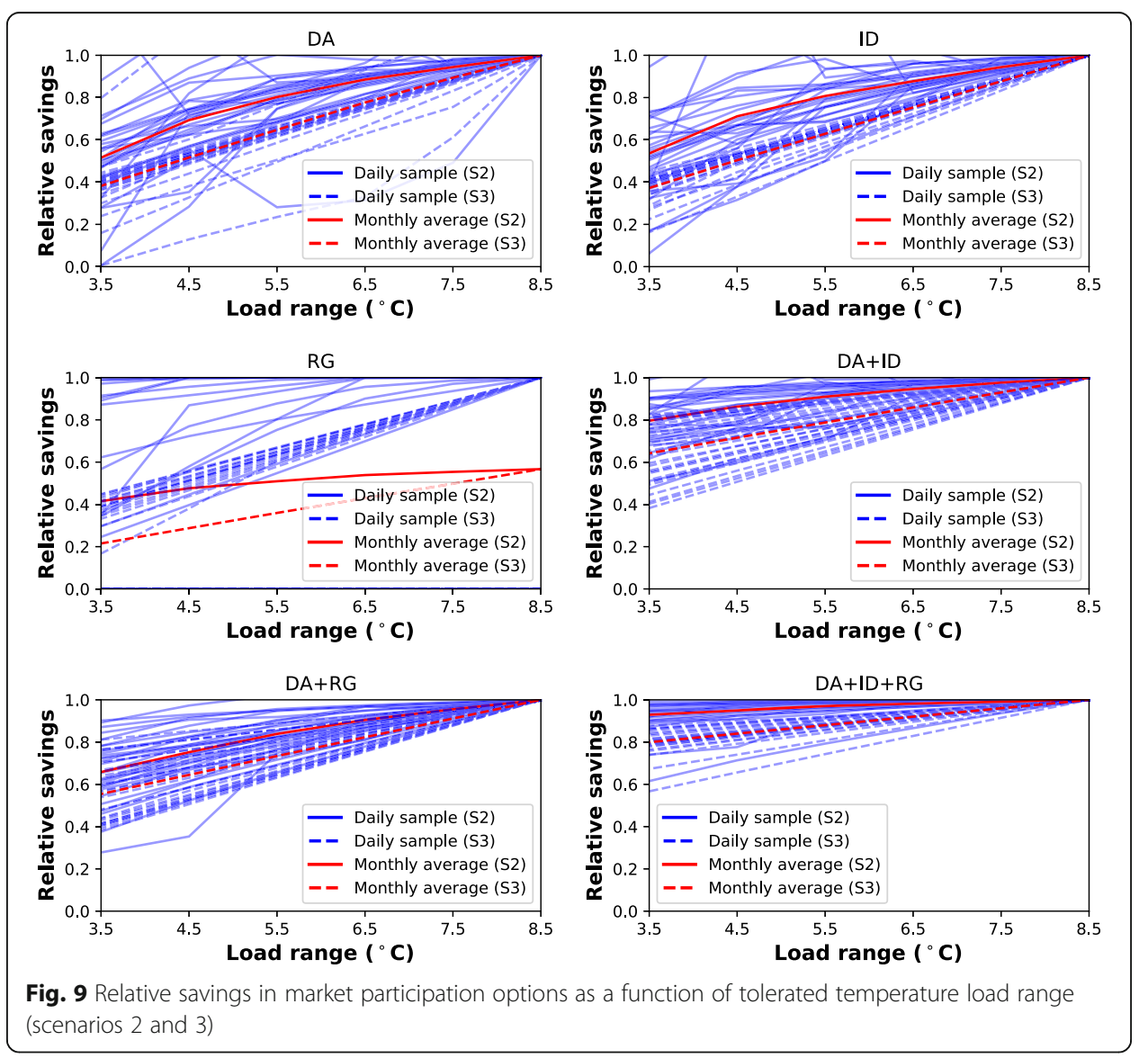


While Eq. 4 shows that savings are directly dependent on the load deviation from the baseload, results in Figs. 8 and 9 show that this load deviation only brings additional savings if it also allows to respect the energy balance constraint (Eq. 8).

Consumers' interest in participating in each of these market options could change with increasing load range flexibility, particularly if the tolerated load range is increased symmetrically around the baseload. However, for the cooling case study this is unlikely due to the product damage caused at sub-freezing temperatures. The decision to participate in a certain market option will depend on the trade-off between possible savings and the risks associated with market participation, as will be discussed next in the discussion section.

\section{Discussion}

The results in this analysis show a nearly systematic improved performance in savings from multiple-market participation options. Higher savings from multiple-market participation compared to single-market participation are also found in (Schwabeneder et al. 2021). Previous findings for consumer participation in single markets also find relatively low savings for the market prices analysed. In (Katz and Kitzing 2016), an aggregator's flexible portfolio optimisation in the Danish day-ahead market in 2016 mentions the difficult business case for aggregators under the given market conditions. A survey of retail and industrial cooling processes in Germany, accompanied by empirical data analysis, concludes that the potential savings from day-ahead market participation are too low to be significant (Grein and Pehnt 2011). Savings from a flexible industrial consumer in the German day-ahead market are reported to be less than $1 \%$ in (Strobel and Abele 2018).

Single-market options only benefit from intra-market price variability, while multiple-market options also benefit from inter-market price variability. From the results, it seems that most savings are generated from inter-market price variability. Increased load-based flexibility, if implemented correctly, allows to benefit more from inter-market price variability, as more loads can be bought and sold at advantageous price differences. However, for the cooling process, the freezing temperature fixed lower bound prevents such flexibility increase in reality, as larger load deviations cannot be balanced out. Increased time-based flexibility allows to benefit more from intramarket price variability, because longer load-shift horizons unlock larger price ranges. Above a certain time-shift interval, price variability stops increasing due to the cyclical nature of electricity consumption, and increased flexibility cannot improve this price range.

Each market option will therefore reach a limit on possible savings, either due to market prices or due to operating requirements. Figures 6, 7, 8, 9 show that this limit on savings is reached at different flexibility values for each market option. Industrial consumers with adjustable flexibility should therefore compare savings from different options at each flexibility level and consider whether further increases in flexibility yield enough marginal benefits in any of the market options.

These observations are drawn from quantitative results specific to a cooling process in a Danish market context during a given time interval and a chosen thermo-electric relationship. However, this deconstruction of consumption flexibility into time-based and load-based flexibility remains valid for a large range of different processes. While 
the impact of these factors on electricity bill savings will depend on the specific market price data and operating conditions considered, the different savings from market options depending on the type and amount of flexibility underline the relevance of comparing market options to find the optimal bidding strategy based on operating conditions.

\section{Potential risks for the market participation options}

The above conclusions from the comparison of market participation options has been drawn based on the assumption of perfect price and market activity forecasts, ensuring bids always get cleared. Yet in reality, bid clearing uncertainty introduces risks, as cleared schedules could be different from process requirements. These mismatches translate into operational costs, either as imbalance settlement payments or as opportunity costs if the process cannot be operated adequately.

Participation in multiple submarkets increases the likelihood of a mismatch between optimal load schedule and cleared schedule, since more bids must be cleared to achieve the desired load schedule. Participation in multiple submarkets can therefore be considered riskier. It appears from Figs. 7 and 8 that the riskier options are also the most lucrative. Since in reality more cautious bidding strategies would be implemented for riskier options, the difference in savings between the different options is expected to be lower.

The willingness to participate in a market option will depend both on expected savings and risks. If expected savings in a market option increase as flexibility increases, the industrial consumer could decide to participate in this option which previously was considered too risky. If this point is reached, the industrial consumer has overcome a market option's risk threshold. This risk threshold can be overcome at different values of flexibility for different market options. Market options yielding lower savings could still be preferred if they overcome the risk threshold at a lower flexibility value. A next step of this analysis should therefore be to quantify a risk threshold for each market option.

Based on the results for time-based flexibility, multiple-market options are relatively insensitive to time-based flexibility, therefore an increase in time-shift capacity is unlikely to encourage more participation in multiple-market bidding. For single-market bidding, changes in participation willingness are most likely to occur when increasing flexibility at low time-based flexibility, where most of the gains in savings occur.

Based on the results from load-based flexibility, participation willingness could increase if the load range is increased symmetrically away from the baseload, since enough savings could be generated to overcome participation risks.

\section{Limitations of optimisation approach}

As stated at the beginning of this paper, the results obtained from this analysis follow an upper-bound approach. The previous section emphasised that the relaxation of the perfect price forecast assumption would make market arbitrage much riskier. Previous studies have dealt with bid clearing uncertainties through scenario generation in stochastic optimisation, often including risk costs in the objective function through a conditional-value-at-risk term (Böhringer et al. 2019; Menniti et al. 2007). However, 
these problems often take large dimensions when a large number of scenarios are used to represent uncertainty (Menniti et al. 2007). Additionally, the problem becomes a multi-objective function when savings from demand response participation must be compared with the costs of unplanned load deviations due to uncleared bids. Cost assessments will also depend on the risk-willingness of the consumer, which includes behavioural factors. Such improvements in evaluation realism require a large amount of additional constraints in the optimisation problem to describe the problem adequately. The optimisation problem then becomes more complex to adapt to different operating conditions.

In (Lund et al. 2017), the prescriptive approach of the optimisation approach is put in contrast with the descriptive approach of simulations: instead of providing one optimal solution, simulations provide a range of solutions based on different parameter scenarios. The final decision on operating conditions is then made outside of the model by the industrial consumers based on simulation results. Leaving the final decision on operating conditions to the consumer would be more aligned with industrial consumers' preferences for keeping control over their processes (Cardoso et al. 2020). Additionally, time-based simulations with progressive information updates would allow to represent the gradual clearing process more realistically and allow industrial consumers to take decisions in real time, based on current operating conditions. This would also allow to relax the assumption of no imbalance, since the consumer could decide to deviate from cleared schedule based on short-term information updates.

Overall, while the upper-bound optimisation approach allows to give a first assessment of different options' economic viability based on a process' range of operating conditions, interesting options should be explored further with more realistic timebased simulations.

\section{Conclusion}

This paper presents an evaluation approach of the economic viability of market options for industrial consumers interested in electricity market participation through demand response. In particular, the analysis focuses on how industrial consumers' operating conditions have an influence on savings from different market options.

Results show that for the analysed data, more savings can be obtained from multiplemarket bidding than single-market bidding and that a large part of savings in multiplemarket bidding seems to come from price differences between submarkets in the same hour. Higher flexibility allows to better exploit price differences between and within submarkets, but the marginal benefit of increasing flexibility depends both on how this flexibility is increased and which market option is considered. Increasing time-shift will mainly favour single-market options at low flexibility values, while increasing the operating load range can benefit all market options, but not all load range increases are beneficial. Submarkets with lower activation frequency, such as the regulating power market in this case study, particularly benefit from increased flexibility. The marginal benefit of increased flexibility eventually drops in each market option when further savings are limited by market prices or operating requirements.

This analysis underlines that savings from demand response can vary strongly depending on the chosen market participation option, and that the preferred market option can change depending on the amount and type of available flexibility under given 
operating requirements. The underlying conclusion is that industrial consumers should compare savings from different market options over their range of operating conditions before selecting a market participation strategy.

This study focused only on the impact of operating requirements on savings in different market options. However, more parameters should be included in further studies to improve the realism of results. To deal with the sequential nature of market clearing, time-base simulations are recommended to model consumers' real-time decision making. The operational risks of each market option should also be quantified, to identify the flexibility threshold above which savings outweigh costs in each market option. More time intervals and industrial processes should be analysed to draw general conclusions on the impact of operating conditions on savings from different market options. Finally, additional submarket options should be considered, including capacitybased submarkets and their interactions with the energy-based submarkets in this study.

\section{Abbreviations}

DA: Day-ahead; ID: Intraday; RG: Regulating power; S1, S2, S3: Scenario 1, Scenario 2, Scenario 3; BL: Baseload; DKK: Danish Krones

Acknowledgments

This study is conducted as part of the Sino-Danish Center university collaboration (https://sdc.university).

\section{About this supplement}

This article has been published as part of Energy Informatics Volume 4, Supplement 2 2021: Proceedings of the Energy Informatics.Academy Conference Asia 2021. The full contents of the supplement are available at https://

energyinformatics.springeropen.com/articles/supplements/volume-4-supplement-2.

\section{Authors' contributions}

NF conceived the research, implemented the models and drafted the first version of the paper. ZM and BNJ supervised the research conception, provided feedback and participated in the paper revision. All authors read and approved the final manuscript.

\section{Funding}

This work is part of the PhD scholarship "A digital twin framework for evaluating industrial consumers' demand response participation: a comparison between Denmark and China", funded by the Sino-Danish Center for Education and Research (SDC) with particular collaboration between University of Southern Denmark and University of Chinese Academy of Sciences.

\section{Availability of data and materials}

The inside temperature data for the cooling process is not publicly available due to the confidentiality agreement with the third-party providing the data. The market prices and activation rates used in the study are available via Energinet's Energi Data Service (https://www.energidataservice.dk/).

\section{Declarations}

Ethics approval and consent to participate

Not applicable.

\section{Consent for publication}

Not applicable.

\section{Competing interests}

The authors declare that they have no competing interests.

\section{Author details}

${ }^{1}$ Center for Energy Informatics, the Maersk Mc-Kinney Moller Institute, University of Southern Denmark, 5230 Odense, Denmark. ${ }^{2}$ Sino-Danish Center for Education and Research, University of Chinese Academy of Sciences, Beijing, China. ${ }^{3}$ Center for Health Informatics, the Maersk Mc-Kinney Moller Institute, University of Southern Denmark, 5230 Odense, Denmark. 
Published: 24 September 2021

\section{References}

ACER (2020) Guidance on the application of regulation (EU) no 1227/2011 of the European Parliament and of the council of 25 October 2011 on wholesale energy market integrity and transparency. Ljubljana: Agency for the Cooperation of Energy Regulators

Bohlayer M, Fleschutz M, Braun M, Zöttl G (2018) Demand side management and the participation in consecutive energy markets-a multistage stochastic optimization approach, 2018 15th International Conference on the European Energy Market (EEM): IEEE, pp 1-5

Böhringer M, Plößer T, Hanson J, Weitzel T, Glock C, Roloff N (2019) Trading strategy for a flexible factory participating in the German balancing and day-ahead market, 2019 54th International Universities Power Engineering Conference (UPEC): IEEE, pp 1-6

Cardoso CA, Torriti J, Lorincz M (2020) Making demand side response happen: a review of barriers in commercial and public organisations. Energy Res Soc Sci 64:101443. https://doi.org/10.1016/j.erss.2020.101443

Danish_Energy_Agency (2020) Liberalisation of the Danish power sector, 1995-2020. An international perspective on lessons learned. Copenhagen: Danish Energy Agency

Ding Z, Sarikprueck P, Lee W-J (2015) Medium-term operation for an industrial customer considering demand side management and risk management, 2015 IEEE/IAS 51st Industrial \& Commercial Power Systems Technical Conference (I\&CPS): IEEE, pp 1-9

DMI (2021) DMI open data developers portal. Available from: https://dmiapi.govcloud.dk/\#!/. Accessed 17 Apr 2021

Domahidi A, Chu E, Boyd S (2013) ECOS: An SOCP solver for embedded systems, 2013 European Control Conference (ECC): IEEE, pp 3071-3076

Energianalyse E (2011) Kortlægning af potentialet for fleksibelt elforbrug i industri, handel og service

Energinet (2007) Regulation A: principles for the electricity market

Energinet (2021a) Energinet data service - ancillary services. Available from: https://www.energidataservice.dk/collections/a ncillaryservices. Accessed 19 Mar 2021

Energinet (2021b) Energi data service. Available from: https:/www.energidataservice.dk/. Accessed 04 Feb 2021

Grein A, Pehnt M (2011) Load management for refrigeration systems: potentials and barriers. Energy Policy 39(9):5598-5608. https://doi.org/10.1016/j.enpol.2011.04.040

IRENA (2017) Adapting market design to high shares of variable renewable energy. International Renewable Energy Agency, Abu Dhabi

Katz J, Kitzing L (2016) Risk implications of investments in demand response from an aggregator perspective. Energy: Expectations and Uncertainty, 39th IAEE International Conference, Jun 19-22, 2016: International Association for Energy Economics

Kirschen DS (2003) Demand-side view of electricity markets. IEEE Trans Power Syst 18(2):520-527. https://doi.org/10.1109/ TPWRS.2003.810692

Krause SM, Börries S, Bornholdt S (2015) Econophysics of adaptive power markets: when a market does not dampen fluctuations but amplifies them. Phys Rev E 92(1):012815. https://doi.org/10.1103/PhysRevE.92.012815

Kühnlenz F, Nardelli PH, Karhinen S, Svento R (2018) Implementing flexible demand: real-time price vs. market integration. Energy. 149:550-565. https://doi.org/10.1016/j.energy.2018.02.024

Li Y-C, Hong SH (2016) Real-time demand bidding for energy management in discrete manufacturing facilities. IEEE Trans Ind Electron 64(1):739-749

Lund H, Arler F, Østergaard PA, Hvelplund F, Connolly D, Mathiesen BV, Karnøe P (2017) Simulation versus optimisation: theoretical positions in energy system modelling. Energies. 10(7):840. https://doi.org/10.3390/en10070840

Lund PD, Lindgren J, Mikkola J, Salpakari J (2015) Review of energy system flexibility measures to enable high levels of variable renewable electricity. Renew Sust Energ Rev 45:785-807. https://doi.org/10.1016/j.rser.2015.01.057

Ma Z, Asmussen A, Jørgensen BN (2015) Industrial consumers' acceptance to the smart grid solutions: case studies from Denmark, 2015 IEEE Innovative Smart Grid Technologies-Asia (ISGT ASIA): IEEE, pp 1-6

Ma Z, Asmussen A, Jørgensen BN (2018) Industrial consumers' smart grid adoption: influential factors and participation phases. Energies. 11(1):182. https://doi.org/10.3390/en11010182

Ma Z, Badi A, Jørgensen BN (2016a) Market opportunities and barriers for smart buildings, 2016 IEEE Green Energy and Systems Conference (IGSEC): IEEE, pp 1-6

Ma Z, Billanes JD, Jørgensen BN (2017a) Aggregation potentials for buildings—business models of demand response and virtual power plants. Energies 10(10):1646

Ma Z, Billanes JD, Kjærgaard MB, Jørgensen BN (2017b) Energy flexibility in retail buildings: From a business ecosystem perspective, 2017 14th International Conference on the European Energy Market (EEM): IEEE, pp 1-6

Ma Z, Friis HTA, Mostrup CG, Jørgensen BN (2017c) Energy flexibility potential of industrial processes in the regulating power market, 6th International Conference on Smart Cities and Green ICT Systems (SMARTGREENS 2017), pp 109-115

Ma Z, Jørgensen BN (2018) Energy flexibility of the commercial greenhouse growers: the potential and benefits of participating in the electricity market, 2018 IEEE Power \& Energy Society Innovative Smart Grid Technologies Conference (ISGT): IEEE, pp 1-5

Ma Z, Prljaca Z, Jørgensen BN (2016b) The international electricity market infrastructure-insight from the nordic electricity market, 2016 13th international conference on the European energy market (EEM): IEEE, pp 1-5

Menniti D, Musmanno R, Scordino N, Sorrentino N, Violi A (2007) Managing price risk while bidding in a multimarket environment, 2007 IEEE Power Engineering Society General Meeting: IEEE, pp 1-10

Nolan S, O'Malley M (2015) Challenges and barriers to demand response deployment and evaluation. Appl Energy 152:1-10. https://doi.org/10.1016/j.apenergy.2015.04.083

Nordpool (2020) Nordpool market data. Available from: https://www.nordpoolgroup.com/Market-data1/Dayahead/Nolumes/ DK/Hourly1111/?view=table. Accessed 25 Nov 2020

O'Connell N, Madsen H, Pinson P, O'Malley M, Green T (2014) Regulating power from supermarket refrigeration, IEEE PES Innovative Smart Grid Technologies, Europe: IEEE, pp 1-6 
Ottesen SØ, Tomasgard A, Fleten S-E (2018) Multi market bidding strategies for demand side flexibility aggregators in electricity markets. Energy. 149:120-134. https://doi.org/10.1016/j.energy.2018.01.187

Paulus M, Borggrefe $F(2011)$ The potential of demand-side management in energy-intensive industries for electricity markets in Germany. Appl Energy 88(2):432-441. https://doi.org/10.1016/j.apenergy.2010.03.017

Pedersen TB, Šikšnys L, Neupane B (2018) Modeling and managing energy flexibility using flexoffers, 2018 IEEE International Conference on Communications, Control, and Computing Technologies for Smart Grids (SmartGridComm): IEEE, pp 1-7

Pinto T, Morais H, Sousa TM, Sousa T, Vale Z, Praça I et al (2015) Adaptive portfolio optimization for multiple electricity markets participation. IEEE Trans Neural Netw Learn Syst 27(8):1720-1733. https://doi.org/10.1109/ TNNLS.2015.2461491

Ropenus S, Jacobsen HK (2015) A snapshot of the Danish energy transition: objectives, markets, grid, support schemes and acceptance. Study

Samad T, Kiliccote S (2012) Smart grid technologies and applications for the industrial sector. Comput Chem Eng 47:76-84. https://doi.org/10.1016/j.compchemeng.2012.07.006

Schwabeneder D, Corinaldesi C, Lettner G, Auer H (2021) Business cases of aggregated flexibilities in multiple electricity markets in a European market design. Energy Convers Manag 230:113783. https://doi.org/10.1016/j.enconman.2020.113 783

Shafie-Khah M, Heydarian-Forushani E, Golshan M, Siano P, Moghaddam M, Sheikh-El-Eslami M et al (2016) Optimal trading of plug-in electric vehicle aggregation agents in a market environment for sustainability. Appl Energy 162:601-612. https:// doi.org/10.1016/j.apenergy.2015.10.134

Shoreh MH, Siano P, Shafie-khah M, Loia V, Catalão JP (2016) A survey of industrial applications of demand response. Electr Power Syst Res 141:31-49. https://doi.org/10.1016/j.epsr.2016.07.008

Strobel N, Abele E (2018) Decentral control strategies for demand-side management by industrial heating and cooling devices with discontinuous operation mode. Proc CIRP 69:360-365. https://doi.org/10.1016/j.procir.2017.11.059

Værbak M, Ma Z, Christensen K, Demazeau Y, Jørgensen BN (2019) Agent-based modelling of demand-side flexibility adoption in reservoir pumping, 2019 IEEE Sciences and Humanities International Research Conference (SHIRCON): IEEE, pp $1-4$

Wang Z, Paranjape R, Sadanand A, Chen Z (2013) Residential demand response: an overview of recent simulation and modeling applications, 2013 26th IEEE Canadian Conference on Electrical and Computer Engineering (CCECE): IEEE, pp $1-6$

Zhang X, Hug G (2015) Bidding strategy in energy and spinning reserve markets for aluminum smelters' demand response, 2015 IEEE Power \& Energy Society Innovative Smart Grid Technologies Conference (ISGT): IEEE, pp 1-5

\section{Publisher's Note}

Springer Nature remains neutral with regard to jurisdictional claims in published maps and institutional affiliations.

\section{Submit your manuscript to a SpringerOpen ${ }^{\circ}$ journal and benefit from:}

- Convenient online submission

- Rigorous peer review

- Open access: articles freely available online

- High visibility within the field

- Retaining the copyright to your article

Submit your next manuscript at $\boldsymbol{\nabla}$ springeropen.com 